\title{
Analysis of the prognostic risk factors of idiopathic membranous nephropathy using a new surrogate end-point
}

\author{
BO ZHANG ${ }^{1 *}$, MING CHENG $^{2 *}$, MING YANG $^{2 *}$, SHUAI HAN ${ }^{3}$, YING-HUI ZHANG ${ }^{2}$, \\ HONG-GUANG SHI ${ }^{4}$, LIANG ZHU ${ }^{1}$ and XUE-ZHI ZHAO ${ }^{2}$
}

\author{
${ }^{1}$ Department of Gastroenterology, Changzheng Hospital Affiliated to the Second Military Medical University; \\ ${ }^{2}$ Department of Nephrology, Changzheng Hospital Affiliated to the Second Military Medical University and the Kidney Institute \\ of CPLA; ${ }^{3}$ Department of Osteology, Changzheng Hospital Affiliated to the Second Military Medical University, \\ Shanghai 200003; ${ }^{4}$ Department of Nephrology, No. 401 Hospital of CPLA, Shandong 266000, P.R. China
}

Received September 15, 2015; Accepted December 4, 2015

DOI: $10.3892 /$ br.2015.555

\begin{abstract}
Idiopathic membranous nephropathy (IMN) is one of the most common causes of nephrotic syndrome (NS) in adults. The latest study of the chronic kidney disease-prognosis consortium showed that a $30 \%$ decrease in the estimated glomerular filtration rate (eGFR) within 2 years could cover more patients and showed a better correlation with end-stage renal disease (ESRD), as compared with serum creatinine (SCr). The aim of the present study was to analyze prognostic factors of ESRD using a 30\% decrease in eGFR within 2 years as the end-point. The medical records of patients who were diagnosed as having IMN by clinical pathology between February 2011 and August 2012 and had been followed up for $\geq 24$ months were analyzed retrospectively. A 30\% decrease in eGFR or the occurrence of ESRD were the end-points. Factors affecting the prognosis were analyzed by the $\chi^{2}$ test and multivariate logistic regression analysis, and the cumulative risk of risk factors was analyzed by Kaplan-Meier curve. A total of 73 patients with IMN were confirmed by clinical pathology. Blood pressure, tubulointerstitial injury area (TIA), glomerular sclerosis ratio, $\mathrm{SCr}$, blood urea nitrogen, cystatin $\mathrm{C}$, serum albumin and 24-h
\end{abstract}

Correspondence to: Professor Liang Zhu, Department of Gastroenterology, Changzheng Hospital Affiliated to the Second Military Medical University, 415 Fengyang Road, Shanghai 200003 , P.R. China

E-mail: zhuliangcz@sina.com

Professor Xue-Zhi Zhao, Department of Nephrology, Changzheng Hospital Affiliated to the Second Military Medical University and the Kidney Institute of CPLA, 415 Fengyang Road, Shanghai 200003, P.R. China

E-mail: zhao_xz1957@126.com

*Contributed equally

Key words: idiopathic membranous glomerulonephritis, glomerular filtration rate, outcome, risk factors, Chinese population urine protein. In total, 28 patients $(38.4 \%)$ reached the observation end-point. Multivariate logistic regression analysis showed that only age $\geq 60$ years, serum albumin $<25 \mathrm{~g} / 1$ and TIA $>25 \%$ were independent risk factors for predicting the occurrence of end-point events in the two groups $(\mathrm{P}<0.05)$, which increased the risk of the occurrence of end-point events in IMN patients by 3.471-, 3.195- and 6.724-fold, respectively. Kaplan-Meier curve showed that the occurrence of end-point events within 2 years was significantly higher in IMN patients whose age was $\geq 60$ years, serum albumin $<25 \mathrm{~g} / \mathrm{l}$ and TIA $>25 \%$ (log-rank $\mathrm{P}=0.004, \mathrm{P}=0.024$ and $\mathrm{P}=0.001)$. The results of the present study revealed that age $\geq 60$ years, low serum albumin concentrations and severe tubulointerstitial injury are independent risk factors for the occurrence of ESRD in IMN patients.

\section{Introduction}

Idiopathic membranous nephropathy (IMN) is an autoimmune glomerulonephropathy, the pathogenesis of which remains unknown. Pathologically, IMN is characterized by immune complex deposition in glomerular basement membrane (GBM) epithelial cells with diffuse thickening of the GBM (1). IMN is one of the main causes for primary nephrotic syndrome (NS) in adults (2), accounting for 9.89-13.3\% of all glomerular nephritis cases in mainland China $(3,4)$.

The onset of IMN is insidious and the prognosis varies significantly. IMN can be spontaneously cured in $25-50 \%$ patients, while immunosuppressant therapy may fail in other patients, in whom the condition may progress gradually to end-stage renal disease (ESRD) (5-7). According to the classic view based on early studies, male gender, age $>50$ years, hypertension, the presence of ultra-large quantities of proteinuria ( $>10 \mathrm{~g} / 24 \mathrm{~h}$ ), and elevation of serum creatinine ( $\mathrm{SCr}$ ) in the beginning of the disease onset are factors unfavorably affecting the prognosis (8). However, the reliability of this conclusion has been challenged by increasing evidence in recent years (9). As all these studies used a 2-fold increase in $\mathrm{SCr}$ within 2 years as the surrogate end-point of ESRD, the sensitivity to prognostic judgment of patients with chronic kidney disease (CKD) is inadequate (9). 
The latest study of the chronic kidney disease prognosis consortium (CKD-PC) identified that a 30\% decrease in the estimated glomerular filtration rate (eGFR) within 2 years was a better surrogate end-point (9). In the present study, this observation end-point was used to follow-up patients with IMN confirmed by clinical pathology in the Kidney Institute of the Chinese People's Liberation Army (Shanghai, China), between February 2011 and August 2012, to explore the correlation between the clinicopathological parameters and the prognosis in IMN patients.

\section{Patients and methods}

Patient selection. Included in the present study were 73 IMN patients aged between 18 and 80 years who presented with glomerular membranous nephropathy, as confirmed by renal biopsy, and received treatment, and whose $\mathrm{SCr}$ was $<445 \mu \mathrm{mol} / 1$ at the time of recruitment. Exclusion criteria were secondary factors (autoimmune diseases, hepatitis B and C, tumors, excessive exposure to organic solvents and undergoing treatment with some medicines that potentially cause secondary membranous nephropathy), patients with complicated diabetes mellitus, and prealbumin $<200 \mathrm{mg} / \mathrm{l}$.

Clinical parameters. Gender, age, blood pressure (BP), 24-h urine protein, serum albumin, blood urea nitrogen (BUN), $\mathrm{SCr}$, eGFR as estimated by the chronic kidney disease epidemiology collaboration (CKD-EPI) equation (10), and cystatin $\mathrm{C}$ (Cyst $\mathrm{C}$ ) of all the included patients were recorded.

Pathological parameters. All the renal biopsy specimens were routinely examined by optical microscopy, immunofluorescence microscopy and electron microscopy. The renal pathology was in accordance with the Ehrenreich criteria. Immunoglobulin G (IgG), IgM, IgA, C3, C4, Clq and fibrin-related antigen were detected by immunofluorescence staining. The percentage of glomerular sclerosis (\% GS), severity of tubulointerstitial injury, the type, intensity and location of immunoglobulin and complement deposition were observed by immunofluorescence, and the location of immune complex deposition was observed by electron microscopy. Tubulointerstitial injury area (TIA) was defined as 4 grades. Tubular atrophy, interstitial fibrosis, interstitial edema, interstitial inflammation and acute tubular injury were each graded semiquantitatively on a scale of $0-3^{+}$based on the $\%$ cortical area affected (absent, $\leq 25,26-50$ and $>50 \%$, respectively) (11).

Treatment. For the initial treatment, all the patients received angiotensin receptor blocker (ARB) therapy following biopsy, with the dose adjusted depending on BP. A 6-month course of treatment with prednisone acetate $(0.5 \mathrm{mg} / \mathrm{kg}$ per day $)$ and cyclophosphamide $(1.0 \mathrm{~g} / \mathrm{m})$ was implemented in patients who presented with one of the following three conditions 6 months after ARB therapy (12): i) 24-h urine protein $>4 \mathrm{~g}$ that remained at a level of $50 \%$ higher than the baseline without showing a declining tendency; ii) the existence of severe, disabling or life-threatening clinical symptoms associated with NS; and iii) a $\geq 30 \%$ elevation in SCr within 6-12 months after confirmation of the diagnosis, but eGFR not $<25-30 \mathrm{ml} / \mathrm{min} / 1.73 \mathrm{~m}^{2}$, and these changes were not due to NS complications.

Follow-up records. Follow-up records included 24-h quantitative proteinuria, serum albumin, BUN and SCr. Complete remission (CR) was defined as urine protein $<0.4 \mathrm{~g} / 24 \mathrm{~h}$ and serum albumin $>35 \mathrm{~g} / 1$ for $\geq 1$ month; partial remission (PR) was defined as urine protein decreasing by $>50 \%$ and quantitative proteinuria $<3.5 \mathrm{~g} / 24 \mathrm{~h}$ and serum albumin $>30 \mathrm{~g} / \mathrm{l}$ for $\geq 1$ month; no response (NR) was defined as persistent proteinuria within the range of nephropathy without reaching the criterion of urine protein for PR.

End-point events. A $30 \%$ decrease in eGFR or entry of ESRD within 2 years was set as the observation end-point. Patients who entered the end-point or those who did not enter the end-point during the 2-year follow-up period were assigned to two groups.

Statistical analysis. All the measurement data were treated using SPSS 19.0 (SPSS, Inc., Chicago, IL, USA). Comparison between the two groups was performed using the $\chi^{2}$ test, and $\mathrm{P}<0.05$ was considered to indicate a statistically significant difference. Statistically significant clinicopathological parameters were tested by stepwise multivariate logistic regression analysis, and $\mathrm{P}<0.05$ was considered to indicate a statistically significant difference. The cumulative risk was analyzed by Kaplan-Meier curve, and the risk difference was tested by log-rank method, using $\mathrm{P}<0.05$ as statistical significance.

Ethical approval. All the participants signed their written consent to participate in the study. The protocol was approved by the Ethics Committee of the Second Military Medical University (Shanghai, China).

\section{Results}

General data. Finally, 73 IMN patients were enrolled in the study, including 44 (60.3\%) males and 29 (39.7\%) females ranging in age from 18 to 80 years with a mean age of $52.8 \pm 15.4$ years at the time of enrollment. The mean follow-up duration after renal biopsy was $15.35 \pm 5.68$ months, ranging from 3 to 25.5 months with a median of 16 months.

Severe hypoproteinemia (albumin $<25 \mathrm{~g} / \mathrm{l}$ ) was observed in 35 (47.9\%) patients, large quantities of proteinuria $(>3.5 \mathrm{~g} / \mathrm{l})$ in $30(41.1 \%)$, microscopic hematuria in 15 (20.5\%), accompanying hypertension in $23(31.5 \%)$, and eGFR $<90 \mathrm{ml} / \mathrm{min} / 1.73 \mathrm{~m}^{2}$ at the time of renal biopsy in $26(35.6 \%)$ patients. Pathological stages I and II were predominant, accounting for $94.5 \%$. GS occurred as an accompanying sign in $35(47.9 \%)$ patients. TIA was $>25 \%$ in 8 patients.

Follow-up status. All the IMN patients received ARB therapy during the follow-up periods, including 55 patients who received prednisone acetate and cyclophosphamide. Following treatment, 28 (38.4\%) patients achieved CR, 21 (28.8\%) achieved PR, and 24 (32.9\%) patients achieved NR in terms of urine protein. During the 2-year follow-up period, 28 (38.4\%) 
Table I. Comparison of baseline data between patients who reached and did not reach the observation end-point.

\begin{tabular}{|c|c|c|c|}
\hline Observation index & Non end-point group $(\mathrm{n}=45), \mathrm{n}(\%)$ & End-point group $(\mathrm{n}=28), \mathrm{n}(\%)$ & P-value \\
\hline Age $\geq 60$ years & $11(22.4)$ & $15(53.6)$ & 0.012 \\
\hline Male & $26(57.8)$ & $18(64.3)$ & 0.581 \\
\hline Hypertension & $12(26.7)$ & $11(39.3)$ & 0.259 \\
\hline Blood urea nitrogen $>5.6 \mathrm{mmol} / \mathrm{l}$ & $15(33.3)$ & $16(57.1)$ & 0.045 \\
\hline Serum creatinine $>97 \mu \mathrm{mol} / 1$ & $4(8.9)$ & $9(32.1)$ & 0.012 \\
\hline Serum albumin $<25 \mathrm{~g} / 1$ & $17(37.8)$ & $18(64.3)$ & 0.027 \\
\hline Proteinuria $>3.5 \mathrm{~g} / 24 \mathrm{~h}$ & $20(44.4)$ & $10(35.7)$ & 0.461 \\
\hline Estimated glomerular filtration rate $<90 \mathrm{ml} / \mathrm{min} \cdot 1.73 \mathrm{~m}^{2}$ & $12(26.7)$ & $14(50.0)$ & 0.043 \\
\hline Serum cystatin $\mathrm{C}>0.86 \mathrm{mg} / \mathrm{l}$ & $24(53.3)$ & $12(42.9)$ & 0.348 \\
\hline Glomerular sclerosis & $20(44.4)$ & $15(53.6)$ & 0.448 \\
\hline Tubulointerstitial injury area $>25 \%$ & $2(4.4)$ & $6(21.4)$ & 0.024 \\
\hline Pathological stage & & & 0.299 \\
\hline I & $11(24.4)$ & $6(21.4)$ & \\
\hline II & $33(73.3)$ & $19(67.9)$ & \\
\hline III & $1(2.2)$ & $3(10.7)$ & \\
\hline
\end{tabular}

Table II. Comparison of the therapeutic effect and the use of immunosuppressants between the two groups.

\begin{tabular}{lccc}
\hline Observation index & $\begin{array}{c}\text { Non end-point } \\
\text { group (n=45), } \\
\mathrm{n}(\%)\end{array}$ & $\begin{array}{c}\text { End-point } \\
\text { group (n=28), } \\
\mathrm{n}(\%)\end{array}$ & P-value \\
\hline Complete remission & $20(44.4)$ & $8(28.6)$ & 0.175 \\
Partial remission & $14(31.1)$ & $7(25.0)$ & 0.575 \\
No response & $11(24.4)$ & $13(46.4)$ & 0.052 \\
Immunosuppressant use & $32(71.1)$ & $23(82.1)$ & 0.288 \\
\hline
\end{tabular}

patients reached the observation end-point (all reached a $30 \%$ decrease in eGFR, and none reached ESRD), and the remaining $45(61.6 \%)$ did not reach the observation end-point.

Comparison of the baseline data between the two groups showed significant differences in the following six clinicopathological parameters: Age, $\geq 60$ years; $\mathrm{SCr},>97 \mu \mathrm{mol} / \mathrm{l}$; EPI-eGFR, <90 ml/min/1.73 $\mathrm{m}^{2}$; BUN, >5.6 mmol/1; serum albumin $<25 \mathrm{~g} / \mathrm{l}$; and TIA, $>25 \%$ (Table I). There was no significant difference between the two groups in terms of the pathological stage (Table I) and the remission rate of urine protein following treatment during the follow-up period (Table II).

Multivariate logistic regression analysis. Multivariate logistic regression analysis of the aforementioned six variants showing statistically significant differences between the two groups demonstrating that age $\geq 60$ years, serum albumin $<25 \mathrm{~g} / 1$ and TIA $>25 \%$ were three independent risk factors predicting the occurrence of the end-point event in IMN patients (Table III).

Kaplan-Meier curve showed that the occurrence rate of the end-point event was significantly higher in IMN patients with age $\geq 60$ years, serum albumin $<25 \mathrm{~g} / 1$ and TIA $>25 \%$ (log-rank $\mathrm{P}=0.004, \mathrm{P}=0.024$ and $\mathrm{P}=0.001$ ) (Figs. 1-3).
Table III. Multivariate logistic regression analysis on idiopathic membranous glomerulonephritis progression to the observation end-point.

\begin{tabular}{lcc}
\hline Observation index & OR value & P-value \\
\hline Tubulointerstitial injury area $>25 \%$ & 6.724 & 0.044 \\
Serum albumin $<25 \mathrm{~g} / \mathrm{l}$ & 3.195 & 0.034 \\
Age $\geq 60$ years & 3.471 & 0.025 \\
Blood urea nitrogen $>5.6 \mathrm{mmol} / 1$ & 0.046 & 0.830 \\
Serum creatinine $>97 \mu \mathrm{mol} / 1$ & 2.157 & 0.142 \\
eGFR $<90 \mathrm{ml} / \mathrm{min} \cdot 1.73 \mathrm{~m}^{2}$ & 0.021 & 0.884
\end{tabular}

eGFR, estimated glomerular filtration rate; OR, odds ratio.

\section{Discussion}

IMN is the most common cause of primary NS in adults (13). The proportion of IMN in primary glomerulonephritis has increased markedly in recent years, accounting for $\sim 20 \%$ of patients receiving renal puncture biopsy (14). The clinical prognosis varies greatly: Approximately one-third of the patients can achieve spontaneous remission, and approximately one-third of the patients remain proteinuric with a relatively stable renal function. Long-term follow-up studies have demonstrated that the remaining $30 \%$ of the patients may progress to ESRD or succumb within 5-10 years (15-18). However, there is not sufficient research on risk factors affecting the prognosis of IMN. The study results from different centers are largely contradictory, and the results obtained from Asian populations alone are not all the same (19-21). The possible reason for these discrepancies may be due to the fact that all these studies used the 2-fold increase in $\mathrm{SCr}$ as the surrogate end-point. Knowing that the phenomenon of 2-fold increase in $\mathrm{SCr}$ is an index with poor sensitivity, Coresh et al (9) conducted a meta-analysis on $\mathrm{SCr}$ 


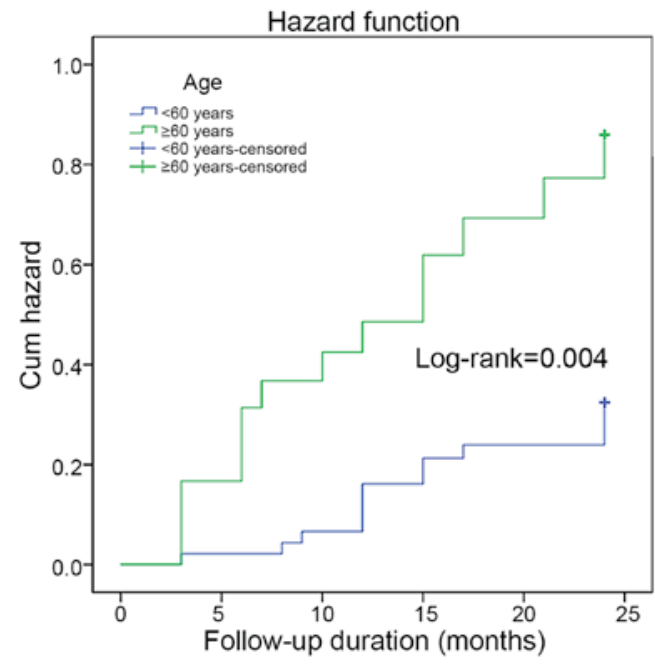

Figure 1. Kaplan-Meier curve analysis. Cumulative risk of renal function progressing to the observation end-point in patients $>60$ years.

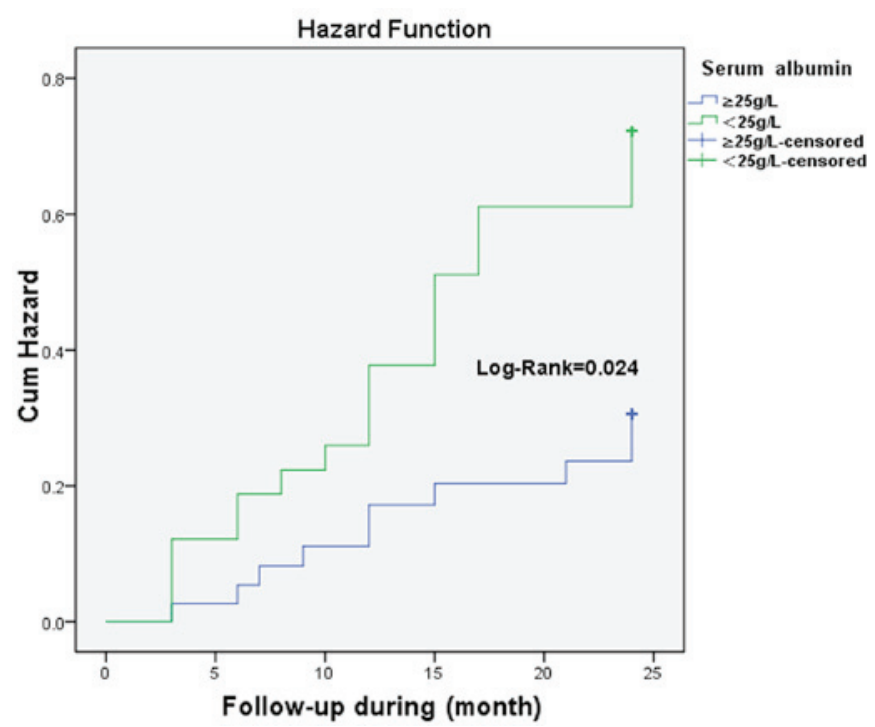

Figure 2. Kaplan-Meier curve analysis. Cumulative risk of renal function progressing to the observation end-point in patients with serum albumin $<25 \mathrm{~g} / 1$.

levels in 28 cohorts of 1.5 million subjects and identified that in CKD patients with either poor (eGFR $<60 \mathrm{ml} / \mathrm{min} / 1.73 \mathrm{~m}^{2}$ ) or $\operatorname{good}\left(\mathrm{eGFR} \geq 60 \mathrm{ml} / \mathrm{min} / 1.73 \mathrm{~m}^{2}\right)$ baseline renal function, the percentage of patients with a 2 -fold increase in $\mathrm{SCr}$ within 2 years was extremely low, accounting for $<1$ and $0.1 \%$, respectively. These figures are by far lower than the actual occurrence. Therefore, this index should not be used as the end-point index to predict the occurrence of ESRD, as it may distort the research results.

According to the suggestion of the CKD-PC, the criterion of a $30 \%$ decrease in eGFR within 2 years was used in the present study as the surrogate end-point. The result showed that its sensitivity was 5-10-fold as high as that of a 2-fold increase in SCr. During the 2-year follow-up period, only 6 patients $(8.2 \%)$ were detected whose $\mathrm{SCr}$ increased by 2-fold, while $28(38.4 \%$ ) patients reached this end-point (a 30\% decrease in eGFR within 2 years) which is consistent with the

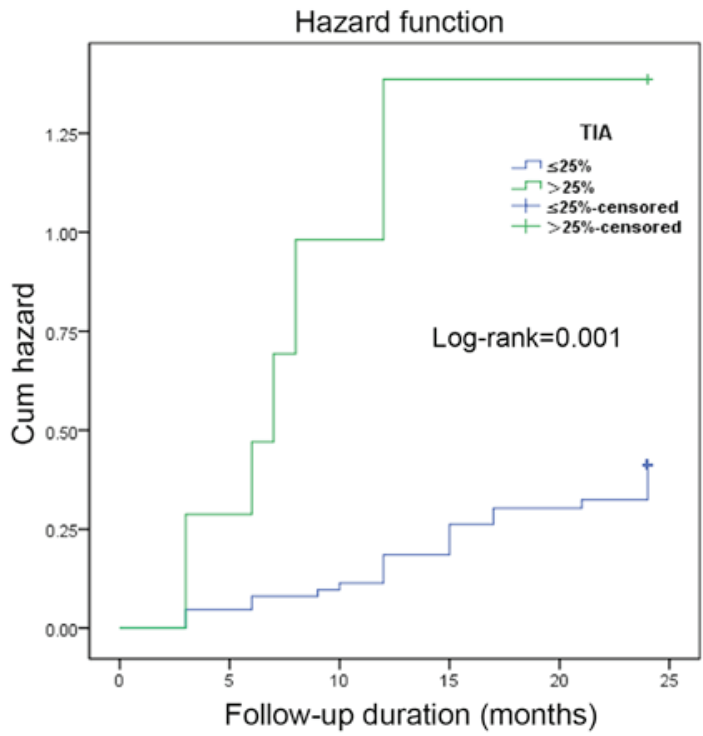

Figure 3. Kaplan-Meier curve analysis. Cumulative risk of renal function progressing to the observation end-point in patients with TIA $>25 \%$. TIA, tubulointerstitial injury area.

study in the literature that approximately one-third of the IMN patient would progress to ESRD.

It was found in the present study that age $\geq 60$ years, $\mathrm{SCr}>97 \mu \mathrm{mol} / 1$, EPI-eGFR $<90 \mathrm{ml} / \mathrm{min} / 1.73 \mathrm{~m}^{2}$, BUN $>5.6 \mathrm{mmol} / 1$, serum albumin $<25 \mathrm{~g} / 1$, and TIA $>25 \%$ are all factors that may increase the risk of end-point event occurrence. However, only age $\geq 60$ years, serum albumin $<25 \mathrm{~g} / 1$ and TIA $>25 \%$ are independent risk factors of end-point event occurrence.

Shiiki et al (19) analyzed the data of 949 Japanese IMN patients and identified that age $\geq 60$ years was the independent risk factor for ESRD, which is consistent with the present result. The risk of end-point event occurrence in patients $>60$ years increased by 3.471 -fold in the present study. An earlier study (22) also supported this finding. An older age is a common risk factor for all patients with chronic glomerulonephritis (23). This may be the result of the synergic effect of decreased renal function associated with physiological aging and the disease itself.

The majority of studies believe that tubulointerstitial injury is an important factor predicting the deteriorating progression of renal function in IMN patients $(24,25)$. Wehrmann et al (24) followed up 334 IMN patients for 5.2 years and revealed that the degree of tubulointerstitial pathological change was the only factor associated with the prognosis. Zuo et al (21) observed 217 IMN patients and found that a change in chronic tubulointerstitial was a high-risk factor contributing to the aggravation and progression of the disease to ESRD. Troyanov et al (26) also reported that the prognosis was poorer in IMN patients whose renal biopsy reported tubulointerstitial pathological change, which is similar to the present study finding. The stepwise multivariate logistic regression analysis in the present study showed that the risk of end-point event recurrence in patients with chronic TIA $>25 \%$ increased by 6.724-fold.

There is no definite conclusion regarding the impact of proteinuria on the prognosis of IMN patients. Studies in the 
20th century $(27,28)$ reported that the long-term prognosis was extremely good in IMN patients without proteinuria within the range of nephropathy, in whom the 10-year kidney survival was as high as $90-100 \%$, which is different from the conclusion drawn from recent studies. Hladunewich et al (29) reported that the prognosis may also be poor in patients whose proteinuria did not reach the range of NS. Polanco et al (30) found that the prognosis may be good in patients whose proteinuria reached $12 \mathrm{~g} / 24 \mathrm{~h}$. The present study did not find that proteinuria within the range of NS had any significant influence on the prognosis; however, the risk of end-point event occurrence in patients with serum albumin $<25 \mathrm{~g} / 1$ increased by 3.195-fold. Kaneko et al (31) identified that biological antioxidant potential (BAP) was closely correlated with the serum albumin concentration in patients with idiopathic nephrotic syndrome, and decreased BAP may aggravate the inflammatory response. Roche et al (32) also found that serum albumin is the most abundant antioxidant in the living body, and therefore hypoalbuminemia may reduce the ability of the body to repair oxidative stress. As this mechanism also exists in IMN patients, hypoalbuminemia may be the consequence of IMN and the cause that promotes the progression of nephropathy.

In conclusion, since 1993, the US Food and Drug Administration has accepted the use of a 2-fold increase in $\mathrm{SCr}$ against the baseline value as the surrogate end-point of progression in chronic nephropathy (33). However, subsequent clinical practices have reported that this criterion is inadequate in various aspects. When a $30 \%$ decrease in eGFR within 2 years could be used as the surrogate end-point, the follow-up period and experimental cost could be reduced markedly, and the experiment efficiency could also be improved (9). Taking the above reasons into account, this criterion was used as the end-point in this study and found that age $>60$ years, the serum albumin concentration $<25 \mathrm{~g} / \mathrm{l}$, and a higher score of chronic tubulointerstitial injury are independent risk factors predicting the progression of IMN patients to ESRD, thus providing an alternative reference for assessing the prognosis of renal disease patients.

\section{Acknowledgements}

The present study was supported by a grant from the National Science Foundation of China to X-Z.Z. (no. 81270765).

\section{References}

1. Kerjaschki D and Farquhar MG: The pathogenic antigen of Heymann nephritis is a membrane glycoprotein of the renal proximal tubule brush border. Proc Natl Acad Sci USA 79: $5557-5561,1982$

2. Heymann W, Hackel DB, Harwood S, Wilson SG and Hunter JL: Production of nephrotic syndrome in rats by Freund's adjuvants and rat kidney suspensions. Proc Soc Exp Biol Med 100: 660-664, 1959

3. Zhou FD, Zhao MH, Zou WZ, Liu G and Wang H: The changing spectrum of primary glomerular diseases within 15 years: A survey of 3331 patients in a single Chinese centre. Nephrol Dial Transplant 24: 870-876, 2009.

4. Li LS and Liu ZH: Epidemiologic data of renal diseases from a single unit in China: Analysis based on 13,519 renal biopsies. Kidney Int 66: 920-923, 2004.

5. Marx BE and Marx M: Prediction in idiopathic membranous nephropathy. Kidney Int 56: 666-673, 1999.
6. Hogan SL, Muller KE, Jennette JC and Falk RJ: A review of therapeutic studies of idiopathic membranous glomerulopathy. Am J Kidney Dis 25: 862-875, 1995.

7. Glassock RJ: Diagnosis and natural course of membranous nephropathy. Semin Nephrol 23: 324-332, 2003.

8. Wasserstein AG: Membranous glomerulonephritis. J Am Soc Nephrol 8: 664-674, 1997.

9. Coresh J, Turin TC, Matsushita K, Sang Y, Ballew SH, Appel LJ, Arima H, Chadban SJ, Cirillo M, Djurdjev O, et al; CKD Prognosis Consortium: Decline in estimated glomerular filtration rate and subsequent risk of end-stage renal disease and mortality. JAMA 311: 2518-2531, 2014.

10. Levey AS, Stevens LA, Schmid CH, Zhang YL, Castro AF III, Feldman HI, Kusek JW, Eggers P, Van Lente F, Greene T, et al; CKD-EPI (chronic kidney disease epidemiology collaboration): A new equation to estimate glomerular filtration rate. Ann Intern Med 150: 604-612, 2009.

11. Stokes MB, Valeri AM, Markowitz GS and D'Agati VD: Cellular focal segmental glomerulosclerosis: Clinical and pathologic features. Kidney Int 70: 1783-1792, 2006.

12. Beck L, Bomback AS, Choi MJ, Holzman LB, Langford C, Mariani LH, Somers MJ, Trachtman H and Waldman M: KDOQI US commentary on the 2012 KDIGO clinical practice guideline for glomerulonephritis. Am J Kidney Dis 62: 403-441, 2013.

13. Hofstra JM, Fervenza FC and Wetzels JF: Treatment of idiopathic membranous nephropathy. Nat Rev Nephrol 9: 443-458, 2013.

14. Pan X, Xu J, Ren H, Zhang W, Xu Y, Shen P, Li X, Wang W, Chen X, Wu P, et al: Changing spectrum of biopsy-proven primary glomerular diseases over the past 15 years: A single-center study in China. Contrib Nephrol 181: 22-30, 2013.

15. Schieppati A, Mosconi L, Perna A, Mecca G, Bertani T, Garattini S and Remuzzi G: Prognosis of untreated patients with idiopathic membranous nephropathy. N Engl J Med 329: 85-89, 1993.

16. Polanco N, Gutiérrez E, Rivera F, Castellanos I, Baltar J, Lorenzo D and Praga M; Grupo de Estudio de las Enfermedades Glomerulares de la Sociedad Española de Nefrología (GLOSEN): Spontaneous remission of nephrotic syndrome in membranous nephropathy with chronic renal impairment. Nephrol Dial Transplant 27: 231-234, 2012.

17. McQuarrie EP, Stirling CM and Geddes CC: Idiopathic membranous nephropathy and nephrotic syndrome: Outcome in the era of evidence-based therapy. Nephrol Dial Transplant 27: 235-242, 2012.

18. Yoshimoto K, Yokoyama H, Wada T, Furuichi K, Sakai N, Iwata Y, Goshima S and Kida H: Pathologic findings of initial biopsies reflect the outcomes of membranous nephropathy. Kidney Int 65: 148-153, 2004.

19. Shiiki H, Saito T, Nishitani Y, Mitarai T, Yorioka N, Yoshimura A, Yokoyama H, Nishi S, Tomino Y, Kurokawa K, et al; Research Group on Progressive Renal Diseases in Japan: Prognosis and risk factors for idiopathic membranous nephropathy with nephrotic syndrome in Japan. Kidney Int 65: 1400-1407, 2004.

20. Eriguchi M, Oka H, Mizobuchi T, Kamimura T, Sugawara K and Harada A: Long-term outcomes of idiopathic membranous nephropathy in Japanese patients treated with low-dose cyclophosphamide and prednisolone. Nephrol Dial Transplant 24: 3082-3088, 2009.

21. Zuo K, Wu Y, Li SJ, Xu F, Zeng CH and Liu ZH: Long-term outcome and prognostic factors of idiopathic membranous nephropathy in the Chinese population. Clin Nephrol 79: 445-453, 2013.

22. Zent R, Nagai $R$ and Cattran DC: Idiopathic membranous nephropathy in the elderly: A comparative study. Am J Kidney Dis 29: 200-206, 1997.

23. Garg AX, Kiberd BA, Clark WF, Haynes RB and Clase CM: Albuminuria and renal insufficiency prevalence guides population screening: Results from the NHANES III. Kidney Int 61: 2165-2175, 2002 .

24. Wehrmann M, Bohle A, Bogenschütz O, Eissele R, Freislederer A, Ohlschlegel C, Schumm G, Batz C and Gärtner HV: Long-term prognosis of chronic idiopathic membranous glomerulonephritis. An analysis of 334 cases with particular regard to tubulo-interstitial changes. Clin Nephrol 31: 67-76, 1989.

25. Ponticelli C, Zucchelli P, Passerini P, Cagnoli L, Cesana B, Pozzi C, Pasquali S, Imbasciati E, Grassi C, Redaelli B, et al: A randomized trial of methylprednisolone and chlorambucil in idiopathic membranous nephropathy. N Engl J Med 320: 8-13, 1989. 
26. Troyanov S, Roasio L,Pandes M,Herzenberg AM and Cattran DC: Renal pathology in idiopathic membranous nephropathy: A new perspective. Kidney Int 69: 1641-1648, 2006.

27. Honkanen E, Törnroth T, Grönhagen-Riska C and Sankila R: Long-term survival in idiopathic membranous glomerulonephritis: Can the course be clinically predicted? Clin Nephrol 41 : 127-134, 1994.

28. Ponticelli C, Passerini P, Altieri P, Locatelli F and Pappalettera M: Remissions and relapses in idiopathic membranous nephropathy. Nephrol Dial Transplant 7 (Suppl 1): 85-90, 1992.

29. Hladunewich MA, Troyanov S, Calafati J and Cattran DC; Metropolitan Toronto Glomerulonephritis Registry: The natural history of the non-nephrotic membranous nephropathy patient. Clin J Am Soc Nephrol 4: 1417-1422, 2009.

30. Polanco N, Gutiérrez E, Covarsí A, Ariza F, Carreño A, Vigil A, Baltar J, Fernández-Fresnedo G, Martín C, Pons S, et al; Grupo de Estudio de las Enfermedades Glomerulares de la Sociedad Española de Nefrología: Spontaneous remission of nephrotic syndrome in idiopathic membranous nephropathy. J Am Soc Nephrol 21: 697-704, 2010.
31. Kaneko K,Kimata T, Tsuji S,Shimo T, Takahashi M and Tanaka S: Serum albumin level accurately reflects antioxidant potentials in idiopathic nephrotic syndrome. Clin Exp Nephrol 16: 411-414, 2012.

32. Roche M, Rondeau P, Singh NR, Tarnus E and Bourdon E: The antioxidant properties of serum albumin. FEBS Lett 582: 1783-1787, 2008.

33. LewisEJ,HunsickerLG,BainRPandRohdeRD; TheCollaborative Study Group: The effect of angiotensin-converting-enzyme inhibition on diabetic nephropathy. N Engl J Med 329: 1456-1462, 1993. 